\title{
The complete cps gene cluster from Streptococcus thermophilus NCFB 2393 involved in the biosynthesis of a new exopolysaccharide
}

\author{
Eva Almirón-Roig, Francis Mulholland, Michael J. Gasson \\ and Annette M. Griffin
}

\begin{abstract}
Author for correspondence: Annette Griffin. Tel: +44 1603255 354. Fax: +44 1603507723 e-mail: annette.griffin@bbsrc.ac.uk
\end{abstract}

Institute of Food Research, Norwich Research Park, Colney Lane, NR4 7UA Norwich, UK

\begin{abstract}
The cpsFGHIJ KL genes from the cps cluster of Streptococcus thermophilus NCFB 2393 involved in the biosynthesis of EPS were identified, cloned and nucleotide sequenced. The complete cps cluster is contained on an $\sim 11.2 \mathrm{~kb}$ chromosomal region which contains 12 ORFs, including the previously cloned CPSABCDE genes. Functions were assigned to some of the predicted gene products on the basis of homology to known sequences as follows: cpsK encodes a protein thought to be involved in the polymerization and export of the polysaccharide; cpsE, cpsF, cpsG, cpsH, cpsI and cps] encode putative sugar transferases. Two insertion sequences, IS1193 and ISS1, were identified within and flanking the $3^{\prime}$ end of the cps cluster respectively. Analysis of the expression of the cpsE gene in Escherichia coli demonstrated that it encodes a glucose-1-phosphate transferase; the enzyme which catalyses the first step in EPS biosynthesis in S. thermophilus NCFB 2393.
\end{abstract}

Keywords: capsule polysaccharide, exopolysaccharide, Streptococcus thermophilus, glycosyltransferase, IS1193

\section{INTRODUCTION}

Streptococcus thermophilus is a thermophilic lactic acid bacterium used as a starter culture in the production of yoghurt and Swiss or Italian-type cheeses. In yoghurt, the presence of exopolysaccharide (EPS) produced by strains of Str. thermophilus leads to an improvement in the viscosity and texture, an increased resistance to mechanical handling and a decreased susceptibility to 'wheying-off'. The chemical structures of five different EPSs produced by different strains of Str. thermophilus have been determined (Bubb et al., 1997; Doco et al., 1990; Lémoine et al., 1997; Low et al., 1998). These were all found to be heteropolymers containing differing amounts of four sugars: glucose, galactose, rhamnose and $N$-acetylgalactosamine. In one case, fucose was also part of the repeat unit. The pathway for EPS biosynthesis in Str. thermophilus is postulated to resemble the $w z y$ -

Abbreviations: CPS, capsule polysaccharide; EPS, exopolysaccharide. The GenBank accession number for the sequence reported in this paper is Y17900. dependent systems reported for O-antigen biosynthesis in Salmonella typhimurium and Escherichia coli (Griffin et al., 1996, Stingele et al., 1996; Whitfield, 1995). These pathways involve the synthesis of individual repeat units on a lipid carrier (undecaprenyl phosphate) by the sequential activities of glycosyltransferase enzymes. Lipid-linked repeat units are then transported across the plasma membrane and exported from the bacterial cell (Whitfield, 1995). Recently, an operon directing the biosynthesis of EPS in the Sfi6 strain of Str. thermophilus has been identified (Stingele et al., 1996), while four complete genes involved in EPS biosynthesis in strain NCFB 2393 have been cloned and sequenced (Griffin et al., 1996). Interestingly, the predicted glycosyltransferase CpsE from NCFB 2393 differed from its homologue in the Sfi6 strain, indicating that these strains may produce EPSs with different chemical structures. We report here the cloning and nucleotide sequence analysis of an $\sim 11 \mathrm{~kb}$ DNA fragment containing the remaining cps genes and genes flanking this cluster in Str. thermophilus NCFB 2393. We compare the sugar composition of the EPS produced by the NCFB 2393 strain to that reported for Sfi6 and several other strains 
of Str. thermophilus. Expression in E. coli was used to identify the glycosyltransferase activity encoded by the NCFB 2393 cpsE gene.

\section{METHODS}

Strains, culture conditions and fermentation. The bacterial strains and vectors used in this work are listed in Table 1. E. coli was grown in LB broth, Terrific broth or LB agar (Sambrook et al., 1989) supplemented with $200 \mu \mathrm{g}$ ampicillin $\mathrm{ml}^{-1}$ when applicable and incubated at $37^{\circ} \mathrm{C}$ aerobically for $18 \mathrm{~h}$. Str. thermophilus was grown in M17 medium (Terzaghi \& Sandine, 1975) supplemented with $1 \%$ sucrose (SM17) and incubated at $42{ }^{\circ} \mathrm{C}$ without shaking. For plates, agar was added at $15 \mathrm{~g} \mathrm{l}^{-1}$. For the production of EPS, Str. thermophilus was grown in MMSt (Cerning et al., 1988) using a 11 fermenter (419 Modular Fermenter; Wood Enterprises), connected to a fermenter meter unit (H. R. Flow Inducer MHRE200; Watson-Marlow). Incubation was at $40^{\circ} \mathrm{C}$ for $24 \mathrm{~h}$ with constant agitation (300 r.p.m.). The $\mathrm{pH}$ was maintained at $5 \cdot 5$ with $5 \mathrm{M} \mathrm{NaOH}$.

EPS isolation and characterization. EPS was isolated as described by Stingele et al. (1996) except that 3 vols acetone were used instead of one and precipitation of EPS was carried out for $18 \mathrm{~h}$ at room temperature. EPS was further purified by passage through a Sephacryl S-400 column (M. Meldgaard, Chr. Hansen's Laboratories). The molecular mass of the EPS was estimated by high-performance size-exclusion chromatography as follows: $1 \mathrm{mg}$ freeze-dried EPS was added to $1 \mathrm{ml}$ $10 \mathrm{mM}$ ammonium bicarbonate (Sigma) and the solution filtered through a $0 \cdot 2 \mu \mathrm{m}$ pore size filter (Millipore). The solution was loaded immediately onto a Polysep column (Phenomenex) for Hewlett Packard HPLC, pre-standarized with a series of pullulan synthetic polysaccharide samples of known molecular mass (Shodex). Neutral sugar analysis of the EPS was performed by GC as described by Fox et al. (1989). The aminosugar content of the EPS was analysed by the method of Ludowieg \& Benmaman (1967).

General DNA manipulations. DNA digestion and ligation was performed as recommended by the enzyme manufacturer. Electroporation into E. coli TG1 cells was carried out as described previously (Dower et al., 1988). Plasmid DNA from E. coli was extracted using SV-Plus miniprep columns from Promega or by centrifugation through caesium chloride/ ethidium bromide gradients (Sambrook et al., 1989). Total DNA was extracted from Str. thermophilus as described by Lewington et al. (1987). PCRs were carried out on Hybaid Omnigene thermocyclers. Template concentration was $600 \mathrm{ng}$ per $50 \mu \mathrm{l}$ reaction for chromosomal DNA; each primer was added to $0 \cdot 1 \mu \mathrm{M}$. AmpliTaq polymerase enzyme (Perkin Elmer; $5 \mathrm{U} \mathrm{ul}^{-1}$ ) was used at $0 \cdot 2 \mu \mathrm{l}$ per $50 \mu \mathrm{l}$ reaction. Annealing and extension conditions were dependent on the nature of primers and the expected product; these were as predicted by Oligo 4.0 for Macintosh.

DNA sequencing and sequence analysis. A primer-walking strategy was used to obtain the DNA sequence from the lambda inserts containing the cps genes. For the sequencing reactions, the Dye Terminator DNA Sequencing Kit (Applied Biosystems) was used and primer was added at $3 \cdot 2$ pmol per $20 \mu \mathrm{l}$ reaction. Lambda DNA template for sequencing was used at $2-3 \mu \mathrm{g}$ per $20 \mu \mathrm{l}$ reaction. Sequencing reactions were electrophoresed and analysed using a Perkin Elmer 373A Fluorescence DNA sequencer. Primer design was checked in Oligo 4.0 for Macintosh. Sequence data were analysed using the Wisconsin GCG package Version 10, Laser Gene Package for the Macintosh version 1.58 (DNAStar), TFASTA (Pearson et al., 1997), BLASTP (Altshchul et al., 1990), CLUSTAL W (Higgins et al., 1994) and PHDsec (Columbia University; http:// www2.ebi.ac.uk). Hydrophobicity domains were determined using DNA STRIDER (version 1.1). Prediction of transmembrane domains and cytoplasmic/extracytoplasmic loops was also carried out using six different programs available from the internet at the ExPASY site (PHDhtm, 'DAS', HMMTOP, TopPred2, TMpred and TMHMM).

Cloning of the Str. thermophilus cps genes. A Lambda DASH II (Stratagene) library was constructed according to the manufacturer's instructions. This was screened for the presence of the $c p s E$ gene, using PCR primers designed from the 3' end of a $4 \mathrm{~kb}$ insert in pAG14 as described previously (Griffin et al., 1993). Lambda DNA from positive clones was extracted as described by Sambrook et al. (1989) or using the $\lambda$-DNA extraction kit (Qiagen), and their inserts sequenced and analysed.

Cloning and expression of cpsE in E. coli. Primers for the amplification of the $c p s E$ gene designed from positions 47074726 and 6188-6206, were as follows: E60 5'-GGGATGATGCGGTTCCTTAT-3' and E61 5'-CCCTTAGAACCAACGATAT-3', respectively. These were used to amplify a $1.48 \mathrm{~kb}$ fragment from lambda clone 9L3, using a proofreading polymerase mixture (Boehringer). This fragment, which contained the entire $c p s E$ gene and the upstream RBS (but no promoter), was cloned into the vector pCR2.1 (Stratagene), in both the sense and antisense orientations in respect of the promoter for the $\beta$-galactosidase gene $\left(\mathrm{P}_{1 \text { ac }}\right)$ (confirmed by nucleotide sequencing). The resulting plasmids were called p13 and p34 respectively. E. coli TG1 cells were transformed with plasmids $\mathrm{p} 13$ and $\mathrm{p} 34$ by electroporation. Diluted $(1 / 10)$ cultures of the clones containing the $c p s E$ gene constructs were grown in $100 \mathrm{ml}$ Terrific Broth until midexponential phase $\left(\mathrm{OD}_{600}=0.475\right)$. At this stage induction was carried out with $1 \mathrm{mM}$ IPTG. Cultures of TG1 containing the pCR2.1 vector or no vector at all were treated in the same way and used as negative controls. Membrane extracts of all the E. coli clones were prepared as described by Kolkman et al. (1996). The efficiency of the membrane extraction was checked by loading $12 \mu \mathrm{l}$ aliquots on a denaturing $10 \%$ polyacrylamide gel as described by Laemmli (1970) and gels stained with Coomassie brilliant blue (Gibco-BRL). The protein concentration was determined using a simplification of the Lowry method (Peterson, 1977).

Glucosyltransferase assay and TLC. Membrane extracts $(40 \mu \mathrm{l}$ of $5 \mathrm{mg} \mathrm{m}^{-1}$ ) from clones containing the $c p s E$ gene construct as well as negative controls were incubated with UDP$\left[{ }^{14} \mathrm{C}\right]$ glucose as described by Kolkman et al. (1996). One-third of the lipid fraction was used for scintillation counting and the remainder was vacuum dried and analysed by TLC. For TLC, the dried reacted samples were resuspended in $100 \mu \mathrm{l}$ butanol and mild hydrolysis was carried out by adding $100 \mu \mathrm{l}$ $50 \mathrm{mM}$ trifluoroacetic acid and incubating at $95^{\circ} \mathrm{C}$ for $20 \mathrm{~min}$. The hydrolysed samples were vacuum dried and resuspended in $10 \mu \mathrm{l} 40 \%$ 2-propanol, $8 \mu \mathrm{l}$ of which was run on a silica gel plate (Merck HPTLC Alufolien Kieselgel 60). The developer used was a mixture of butanol/ethanol/water $(5: 3: 2$ by vol.). Standards of monosaccharides ( $40 \mu \mathrm{g}$ each) were run simultaneously. Detection of radioactivity was done by exposing an X-ray sensitive film directly to the TLC plate, previously sprayed with a $\beta$-enhancer spray $\left(E n^{3} H a n c e\right.$, New England Nuclear), for $5 \mathrm{~d}$ at $-80^{\circ} \mathrm{C}$. The standards were visualized by spraying with $5 \%$ sulfuric acid in ethanol and heating at 
Table 1. Bacterial strains and vectors used in this study

\begin{tabular}{|c|c|c|}
\hline Strain/vector & Description & Source \\
\hline \multicolumn{3}{|l|}{ Strains } \\
\hline \multicolumn{3}{|l|}{ E. coli strains } \\
\hline FI9070 & E. coli $\mathrm{TG} 1 / \mathrm{pAG} 14$ & A. Griffin \\
\hline FI9298 & E. coli $\mathrm{TG} 1 / \mathrm{p} 13$ & This study \\
\hline FI9299 & E. coli $\mathrm{TG} 1 / \mathrm{p} 34$ & This study \\
\hline TG1 & $\begin{array}{l}\Delta(\text { lac-pro } A B), \text { supE, thi, hsd } \Delta 5, \mathrm{~F}^{\prime}\left[\operatorname{tra} \Delta 36 \text { pro }^{+} B^{+}\right. \\
\left.\text {lacl }^{\mathrm{q}} \text { lac } \mathrm{Z} \Delta \mathrm{M} 15\right]\end{array}$ & Gibson (1984) \\
\hline $\begin{array}{l}\text { XL1-Blue } \\
\text { MRA (P2) }\end{array}$ & $\begin{array}{l}\Delta(m c r C B-h s d M R-m r r) 173, \text { end } A 1, \text { supE44, thi- } 1, \\
\text { gyrA96, relA1, lac (P2 lysogen) }\end{array}$ & Stratagene \\
\hline \multicolumn{3}{|c|}{ Str. thermophilus strain } \\
\hline NCFB 2393 & EPS-producing strain from dairy starter & IFR culture collection \\
\hline \multicolumn{3}{|l|}{ Vectors } \\
\hline p13 (pFI2172) & $\begin{array}{l}5.3 \mathrm{~kb} ; \text { pCR } 2.1 \text { containing cpsE from NCFB } 2393 \\
\text { under } \mathrm{P}_{\text {lac }}\end{array}$ & This study \\
\hline p34 (pFI2173) & $\begin{array}{l}5.3 \mathrm{~kb} \text {; as p13 but the insert is in the opposite } \\
\text { orientation to } \mathrm{P}_{\text {lac }}\end{array}$ & This study \\
\hline pAG14 & $\begin{array}{l}6.7 \mathrm{~kb} ; \text { pUC18 containing } 4 \mathrm{~kb} \text { EcoRI fragment from } \\
\text { NCFB } 2393 \text { for EPS biosynthesis }\end{array}$ & Griffin et al. (1996) \\
\hline pCR2.1 & $3.9 \mathrm{~kb}$; Amp and $\mathrm{Km}$ resistance, TA cloning vector & Invitrogen \\
\hline Lambda DASH & $\lambda$ replacement vector. Accepts fragments of $9-23 \mathrm{~kb}$ & Stratagene \\
\hline
\end{tabular}

$110^{\circ} \mathrm{C}$ for $10 \mathrm{~min}$. The assays described here were repeated and identical results were obtained.

\section{RESULTS AND DISCUSSION}

\section{Analysis of EPS produced by NCFB 2393}

Using the fermentation conditions outlined in the Methods, a maximum of $300 \mathrm{mg} \mathrm{EPS}^{-1}$ was obtained from NCFB 2393 cultures. Prior passage of NCFB 2393 (on a daily basis) through MMSt medium, at least five times, was required to achieve this level of EPS. Chemical analysis of the EPS showed that it consists of heptasaccharide repeating units containing the sugars GalNAc, Gal, Rha and Glc in a ratio of $1: 1: 2: 3$. Such a repeat unit has not been reported before for any of the EPSs produced by the Sfi6, Sfi39, Sfi12, OR901 and MR-1C strains of Str. thermophilus (Doco et al., 1990; Lémoine et al., 1997; Bubb et al., 1997; Low et al., 1998). Indeed all of these Str. thermophilus strains contain variation in the sugar composition, ratio of sugars, presence/absence of branches and type of linkages between sugar units of the EPS repeat unit. The molecular mass of the sample was estimated by high-performance size-exclusion chromatography to be $\sim 2 \times 10^{5} \mathrm{Da}$. This was lower than the published $1 \times 10^{6}$ Da reported for the Sfi6 strain (Doco et al., 1990) and the $2 \times 10^{6}$ Da reported by Lémoine et al. (1997) for the Sfi12 and Sfi39 strains. Since the functional properties of a polysaccharide are influenced both by the chemical composition and the molecular mass (Sutherland, 1996), the NCFB 2393 polymer identified here is likely to display novel functional properties. Additional experiments are under way to demonstrate this.

\section{Nucleotide sequence analysis of the cps cluster}

In a previous study, we identified, cloned and nucleotide sequenced a 4074 bp chromosomal fragment containing part of the cps gene cluster (Griffin et al., 1996). To identify the remaining genes, primers designed from the 3' end of the NCFB 2393 cpsE gene were used to screen a lambda library of Str. thermophilus genomic DNA. This was used to identify three positive lambda clones; $\lambda$ 9L3, $\lambda 3 \mathrm{~K} 1$ and $\lambda 8 \mathrm{FJ} 1$ (see Fig. 1). Nucleotide sequencing of the inserts from the lambda clones was performed to obtain the complete sequence data for a $14.62 \mathrm{~kb}$ region. Analysis of these sequence data revealed the presence of $16 \mathrm{ORF}$ including the $3^{\prime}$ end of $c p s A$ and the $c p s B C D E$ genes previously reported by Griffin $e t$ al. (1996) with strong conformity with the streptococcal codon-usage table (not presented) (Fig. 1). Potential ribosome-binding sites were identified upstream of all genes (see accession no. Y17900) and putative promoters were identified upstream of six genes (see Fig. 1 and accession no. Y17900). An AT rich region, 5'-AAAACGTTTTTTTGTTTTTTTTTGAAAAAAA-3', similar to the consensus sequence of an upstream promoter (UP) element, 5'-NNAAA(AT) (AT)T(AT)TTTTNNAAAANNN-3' (Estrem et al., 1998) was identified upstream of the -35 box of the $c p s A$ gene between positions -72 and -42 . UP elements have been reported to stimulate promoter activity up to 30-fold, and are found both in Gram-negative and Gram-positive bacteria (Estrem et al., 1998). Thus strong transcription may occur from the cpsA promoter, resulting in the generation of a single long transcript. The short intergenic spacing between cps genes suggestive of translational coupling, supports this view. In Staphylococcus 


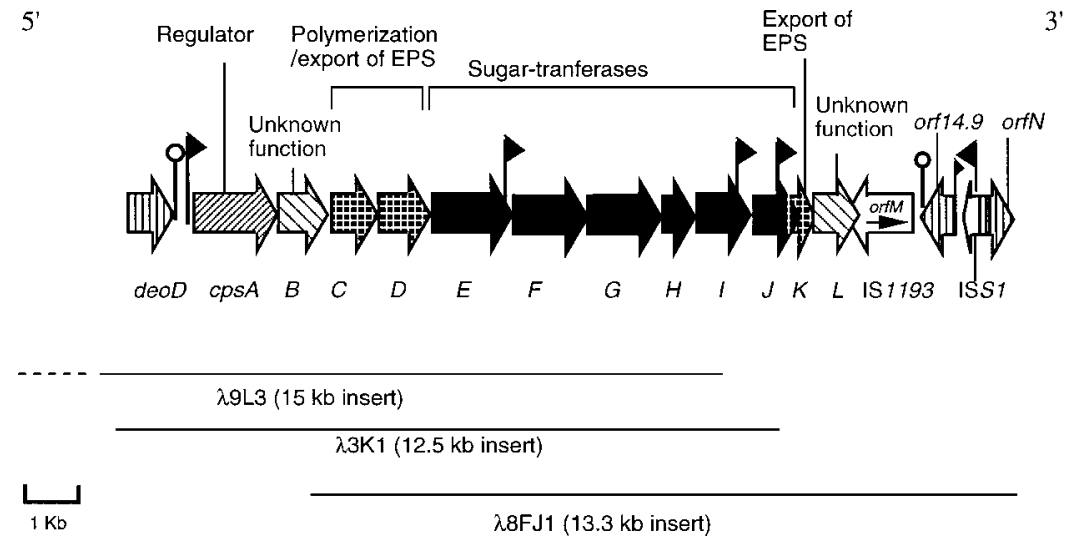

Fig. 1. Genetic organization of the EPS gene cluster in Str. thermophilus NCFB 2393. Lambda clones which contain the cps genes are shown below. Vertically hatched arrows represent flanking genes outside the cps cluster. Flags represent putative promoters. Drumsticks represent putative transcription terminators for deoD and orf14.9. aureus, Streptococcus pneumoniae type 1 and Str. thermophilus Sfi6, it has been shown that expression of the eps or cps gene loci results in a single transcriptional unit despite the presence of putative promoter sequences within the operons (Muñoz et al., 1997; Sau et al., 1997; Stingele et al., 1999). No hairpin loops resembling putative rho-independent transcription terminators were found within the cps genes; however one was identified downstream of orf14.9.

\section{Sequence analysis of the cps genes}

The cpsE, F, G, $H$ and $I$ genes encode proteins with predicted molecular masses of $51 \cdot 8,44 \cdot 6,42 \cdot 6,21 \cdot 3$ and $37 \cdot 8 \mathrm{kDa}$ respectively. When the amino acid sequences of these were compared to the databases, all showed homology to sugar transferases from a variety of different organisms (see Table 2). Given that the NCFB 2393 EPS contains the sugars GalNAc, Gal, Rha and Glc in a ratio of $1: 1: 2: 3$, we expected to find one GalNAc transferase, one galactosyltransferase, two rhamnosyltransferases and three glucosyltransferases.

Analysis of CpsE. CpsE is homologous at the amino acid level, to a large number of undecaprenyl-glucosyl-1phosphate transferases from a large number of different species (Table 2). These proteins catalyse the first step in polysaccharide biosynthesis in these organisms. Comparison of hydrophobicity plots of the amino acid sequence of NCFB 2393 CpsE with those from homologous glycosyltransferases, showed that CpsE from NCFB 2393, CpsE from Str. pneumoniae type 23F, CpsE from Str. pneumoniae type 14 and WbaP from Salmonella enterica are highly related along their entire length (Fig. 2). By homology to WbaP, which was shown to be bifunctional (Wang et al., 1996), CpsE from NCFB 2393 could have the transferase activity assigned to the C-terminal domain and a role in the release of the repeat unit from the lipid carrier assigned to the N-terminal domain. EpsD from Lactococcus lactis NIZO B40, ExoY from Rhizobium meliloti and EpsE from Str. thermophilus Sfi6 probably are not bifunctional since these contain only the C-terminal region with the glycosyltransferase activity.
The C-terminal region of NCFB 2393 CpsE also contained a conserved catalytic motif DXD (residues 342-344) preceded by three hydrophobic amino acids (MFXM). This domain was found to be conserved by a diverse range of glycosyltransferase families, both prokaryotic and eukaryotic (Wiggins \& Munro, 1998). A second putative catalytic region containing a pair of charged residues, Glu and Asp (residues 386 and 438 respectively) previously reported to be within a catalytic site in $\beta$-glycosyltransferases (Saxena et al., 1995; Van Kranenburg et al., 1999) was also identified.

The topological model of CpsE (Fig. 3), depicts CpsE spanning the cytoplasmic membrane five times (segments TM I, II, III, IV and V) and having two large loops, the first one extracytoplasmic, the second one intracytoplasmic (C-terminal region). The transmembrane domains are composed mainly of hydrophobic residues, which are predicted to adopt an $\alpha$-helix conformation. The C-terminal domain, containing the active site, is in the cytoplasm. This contains three domains, $\mathrm{A}, \mathrm{B}$ and $\mathrm{C}$, reported to be common to glycosyltransferases by Wang et al. (1996). Domains A and $B$ are reported to be associated with the interaction of the glycosyltransferase with the membrane lipid, while block $C$ seems to be specific for the transferred sugar. The model presented here is in agreement with reports that EPS biosynthesis occurs at the internal side of the cytoplasmic membrane, with subsequent translocation of the repeat unit across the membrane (Kolkman et al., 1997; Stingele et al., 1996).

Analysis of CpsF-CpsJ. CpsF and CpsG displayed greatest similarity to a rhamnosyltransferase and an N-acetylgalactosyltransferase respectively (Table 2 ), therefore it is reasonable to assign these enzyme activities to these proteins. Biochemical analysis will be required to confirm these predictions. CpsH displayed high similarity to a number of different glucosyltransferases (Table 2), therefore it seemed logical to predict that this represents the second of the three expected glucosyltransferases. CpsI had highest homology to galactosyltransferases (Table 2), therefore it may be the single galactosyltransferase expected in this system. However, 
Table 2. Amino acid homologies for the gene products of the Str. thermophilus NCFB 2393 cps cluster and flanking regions

Und-1P-Glc transferase, undecaprenyl-P-glucosyl-1-phosphate transferase; Cyt/ubiquit oxidase, cytochrome/ubiquitol oxidase; NADH-ubiquinone OR, NADH-ubiquinone oxidoreductase.

\begin{tabular}{|c|c|c|c|c|c|c|}
\hline \multicolumn{4}{|c|}{ Product amino acid highest homologies } & \multirow[t]{2}{*}{ Species } & \multirow[t]{2}{*}{ Function of homologue } & \multirow{2}{*}{$\begin{array}{c}\text { Accession } \\
\text { no. }\end{array}$} \\
\hline $\begin{array}{l}\text { Protein from } \\
\text { strain } 2393\end{array}$ & $\begin{array}{c}\text { Highest } \\
\text { homology to }\end{array}$ & $\begin{array}{c}\text { Similarity } \\
(\%)\end{array}$ & $\begin{array}{c}\text { Identity } \\
(\%)\end{array}$ & & & \\
\hline \multirow[t]{2}{*}{ DeoD } & DeoD & 99 & 98 & Str. thermophilus Sfi6 & Nucleotide metabolism & Q56037 \\
\hline & DeoD/Pnp & 89 & 74 & L. lactis subsp. cremoris & Nucleotide metabolism & O32810 \\
\hline \multirow[t]{4}{*}{ CpsE } & Cps23E & 75 & 57 & Str. pneumoniae $23 \mathrm{~F}$ & Und-1P-Glc transferase & AF030373 \\
\hline & Cps14E & 74 & 55 & Str. pneumoniae S14 & Und-1P-Glc transferase & P72513 \\
\hline & EpsE & 63 & 43 & Str. thermophilus Sfi6 & Und-1P-Glc transferase & U40830 \\
\hline & GumD & 42 & 30 & $X$. campestris & Und-1P-Glc transferase & U22511 \\
\hline \multirow[t]{4}{*}{ CpsF } & CpsT & 85 & 57 & Str. pneumoniae 23F & Rhamnosyltransferase & AF030373 \\
\hline & OrfY & 63 & 47 & Str. mutans AB631 & Unknown & AB000631 \\
\hline & EpsF & 53 & 23 & Str. thermophilus Sfi6 & Glucosyltransferase & U40830 \\
\hline & Cps23F & 47 & 17 & Str. pneumoniae 23F & Mannosyltransferase & AF030373 \\
\hline \multirow[t]{4}{*}{ CpsG } & OrfX & 45 & 26 & Bacillus subtilis 60015 & Spore coat biosynthesis & P46915 \\
\hline & EpsG & 51 & 25 & Str. thermophilus Sfi6 & $\alpha$-GalNAc transferase & U40830 \\
\hline & VipC & 46 & 24 & Sal. typhimurium & LPS biosynthesis & Q04975 \\
\hline & RfaK (WaaK) & 48 & 23 & Sal. typhimurium & 1,2-GlcNAc transferase & P26470 \\
\hline \multirow[t]{4}{*}{$\mathrm{CpsH}$} & Hi1244 & 64 & 38 & Haemophilus influenza & Unknown & P44134 \\
\hline & Cps19K & 50 & 25 & Str. pneumoniae 19F & Epimerase & U09239 \\
\hline & Cps19E & 51 & 24 & Str. pneumoniae 19F & Glucosyltransferase & U09239 \\
\hline & Cps14E & 50 & 22 & Str. pneumoniae S14 & Glucosyltransferase & P72513 \\
\hline \multirow[t]{3}{*}{ CpsI } & Cps14J & 54 & 36 & Str. pneumoniae S14 & Galactosyltransferase & X85787 \\
\hline & EpsI & 55 & 33 & Str. thermophilus Sfi6 & Glucosyltransferase & U40830 \\
\hline & EpsG & 57 & 33 & L. lactis NIZO B40 & Glucosyltransferase & U93364 \\
\hline \multirow[t]{3}{*}{ Cps J } & Gtf-s & 47 & 21 & Streptococcus sobrinus & Dextransucrase precursor & P29336 \\
\hline & $91 \mathrm{kDa}$ protein & 49 & 20 & Saccharomyces cerevisiae & Unknown & P53243 \\
\hline & RfbG (WbbG) & 48 & 18 & Shi. flexneri $2 \mathrm{a}$ & Di-rhamnosyltransferase & X71970 \\
\hline \multirow[t]{4}{*}{ CpsK } & Nup133 & 54 & 29 & Sac. cerevisiae & Pore protein & P36161 \\
\hline & CaaX & 54 & 26 & Sac. cerevisiae & Prenyl endoprotease & P47154 \\
\hline & RfbX (Wzx) & 47 & 20 & Shi.flexneri $2 \mathrm{a}$ & LPS transport & X71970 \\
\hline & Yeast protein & 46 & 17 & Debaryomyces occidentalis & $\mathrm{K}^{+}$-affinity transporter & P50505 \\
\hline CpsL & RfaS (WaaS) & 52 & 27 & E. coli $\mathrm{K}-12$ & LPS outer core assembly & P27126 \\
\hline \multirow[t]{4}{*}{ OrfM } & $\begin{array}{l}\text { Undescribed } \\
\text { ORF }\end{array}$ & 95 & 91 & Str. thermophilus CNRZ 368 & Unknown & Y13713 \\
\hline & $\mathrm{CYOB}$ & 53 & 29 & E. coli $\mathrm{K}-12$ & Cyt/ubiquit oxidase & P18401 \\
\hline & GR78 & 41 & 24 & Kluyveromyces lactis & Glc-regulated precursor & P22010 \\
\hline & HSP70 & 40 & 23 & Glycine max (soybean) & Heat Shock protein 70 & P26413 \\
\hline \multirow[t]{3}{*}{ Orf14.9 } & Orf14.9 & 97 & 96 & Str. thermophilus Sfi6 & Unknown & U40830 \\
\hline & VanZ & 59 & 33 & $\begin{array}{l}\text { Enterococcus faecium } \\
\text { BM4147 }\end{array}$ & Antibiotic resistance & Q06242 \\
\hline & $\mathrm{Nu} 5 \mathrm{M}$ & 57 & 26 & Caenorhabditis elegans & NADH-ubiquinone OR & P24896 \\
\hline OrfN & Ypud & 51 & 27 & B. subtilis & Unknown & P17616 \\
\hline
\end{tabular}

it also contained an $\mathrm{AX}_{7} \mathrm{LDXD}$ motif reported to be found in the $\beta$-glucosyltransferase and cellulose synthase superfamilies (Becker et al., 1997; Wiggins \& Munro, 1998). This could imply that CpsI could be the third glucosyltransferase, thus a detailed biochemical analysis will be required to establish which sugar CpsI transfers. While CpsE-CpsI clearly encode five of the seven sugar transferases, the identity of the remaining two transferases is not so clear. Good candidate sugar transferases are CpsJ and CpsL. CpsJ had homology to dextransucrase, a processive glucosyltransferase enzyme. This could indicate that CpsJ may transfer more than one sugar unit (and so account for the two remaining transferases). Transfer of more than one sugar unit has been reported for glycosyltransferases from other systems, for example RfbG (WbbG) from Shigella flexeneri transfers two consecutive rhamnosyl units (Morona et al., 1995). 


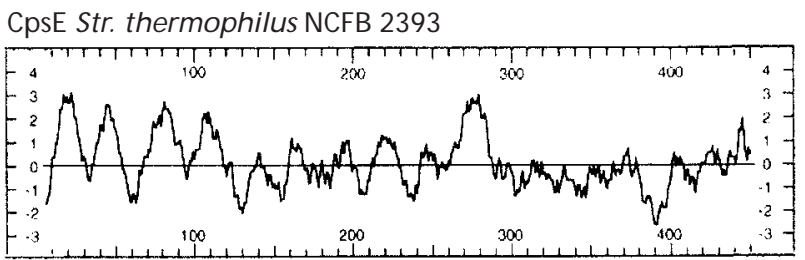

CpsE Str. pneumoniae type 23F

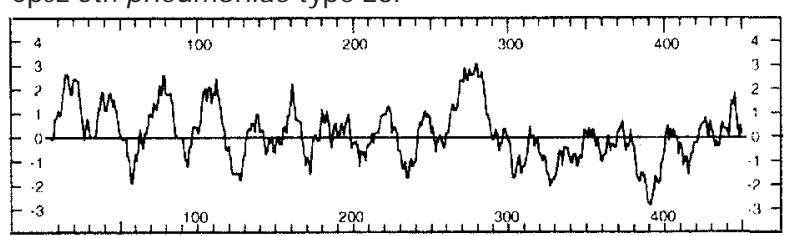

CpsE Str. pneumoniae serotype 14

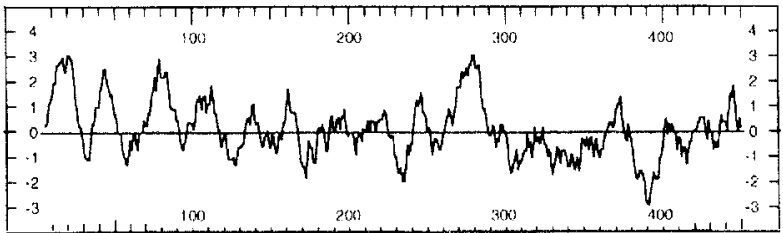

WbaP (RfbP) Sal. enterica LT-2

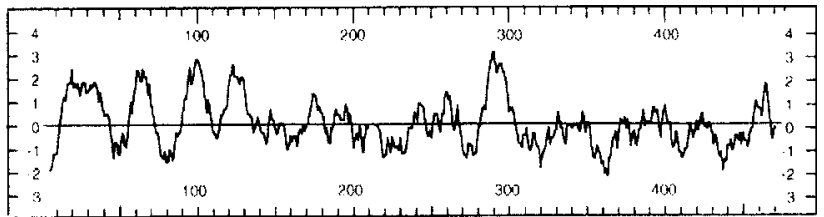

EpsD L. lactis NIZO B40

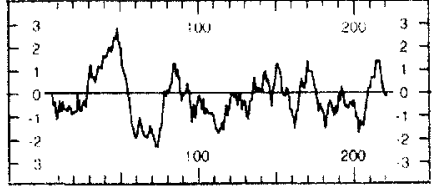

ExoY

R. meliloti

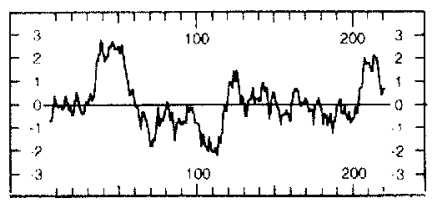

EpsE

Str. thermophilus Sfi6

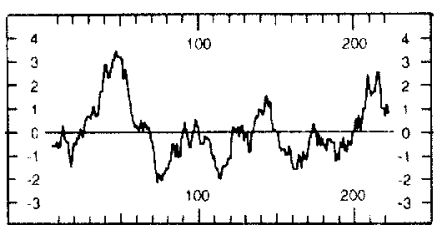

Fig. 2. Hydrophobicity plots of CpsE and CpsE proteins from Str. pneumoniae type 23F (Coffey et al., 1998), Str. pneumoniae serotype 14 (Kolkman et al., 1997), and WbaP from Sal. enterica (Wang et al., 1996), EpsD from L. Iactis NIZO B40 (Van Kranenburg et al., 1997), ExoY from R. meliloti (Mueller et al., 1993) and EpsE from Str. thermophilus Sfi6 (Stingele et al., 1996).

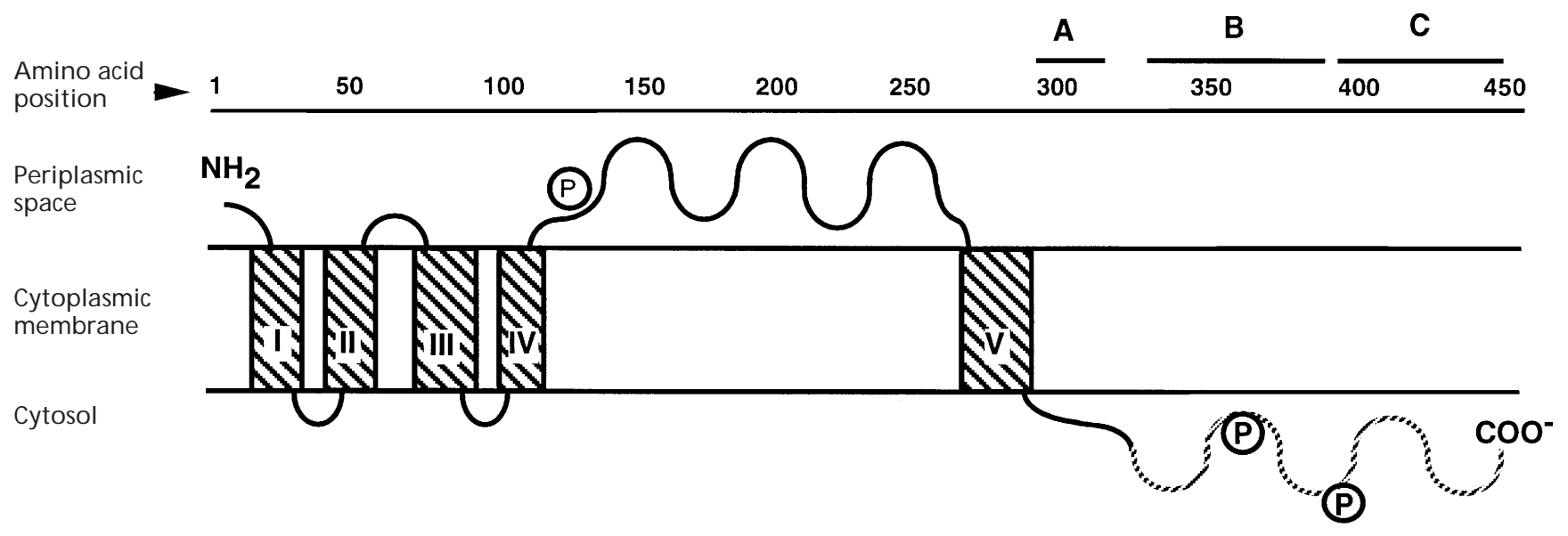

Fig. 3. Putative topology of the CpsE glycosyltransferase from Str. thermophilus NCFB 2393. The protein is predicted to span the membrane five times (transmembrane fragments I-V), with an extracytoplasmic loop plus a cytosolic loop containing the catalytic domain. Domains A and B represent regions of predicted interaction with membrane lipid; domain C represents a region of predicted glucosyltransferase activity (Wang et al., 1996). The dotted line represents a region with a high number of conserved residues.

Analysis of cpsK and cpsL. The $c p s K$ and $c p s L$ genes encode proteins with predicted molecular masses of $14 \cdot 0$ and $35 \cdot 0 \mathrm{kDa}$ respectively. When the amino acid se- quence of $c p s K$ was compared to the databases (see Table 2), similarity to several proteins involved in transport was detected. CpsL displayed significant 


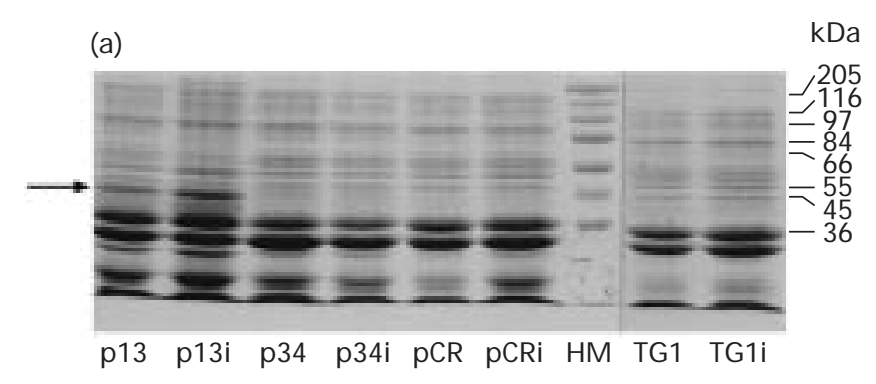

(b)

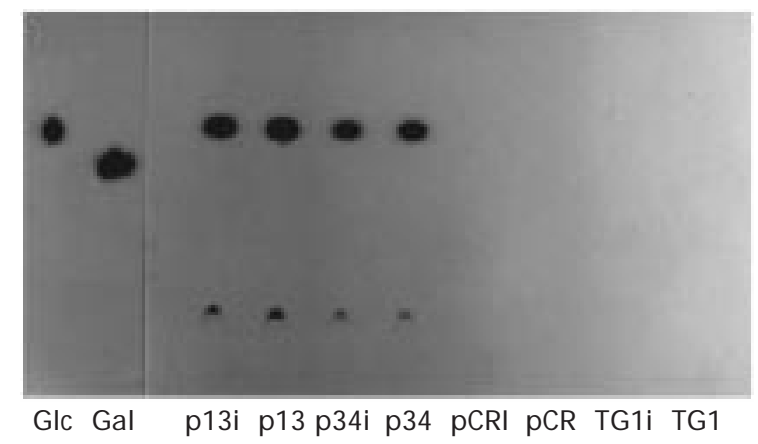

Fig. 4. Expression and functional analysis of cpsE from Str. thermophilus in E. coli. (a) SDS-PAGE ( $10 \%$ acrylamide) of E. coli TG1 cell extracts containing cpsE gene constructs and $\mathrm{E}$. coli negative controls. (b) TLC analysis of sugar-lipid intermediates from the same E. coli clones. p13, NCFB 2393 cpsE gene in the same orientation as $\mathrm{P}_{\text {laci }}$ p34, cpsE gene in the opposite orientation to $\mathrm{P}_{\mathrm{lac}} ; \mathrm{pCR}$, clone containing the $\mathrm{pCR} 2.1$ plasmid with no insert; TG1, E. coli TG1 cells with no plasmid; HM, high molecular mass protein marker (in $\mathrm{kDa}$ ); i indicates that the cultures were induced with $1 \mathrm{mM}$ IPTG. Expressed CpsE is marked with an arrow in (a).

homology to only one protein: WaaS from the LPS biosynthetic pathway of E. coli. A specific function has not been assigned to WaaS, however it has been suggested that it may act as an accessory protein required for the assembly of outer-core oligosaccharide, interacting either with glycosyltransferases or with the inner core LPS moiety (Pradel et al., 1992). Alternatively, Heinrichs et al. (1998) speculate that WaaS may be a rhamnosyltransferase, thus CpsL may be a rhamnosyltransferase. The position of a glycosyltransferase downstream of a putative export gene has been reported before for the cps/eps clusters of L. lactis and Str. pneumoniae (Van Kranenburg et al., 1999; Morona et al., 1999). More experiments are required to resolve the function of cpsL.

\section{Expression of cpsE in E. coli}

The NCFB 2393 cpsE gene was cloned into a high copy number vector and expressed in E. coli TG1. Expression from plasmid p13 (containing cpsE under the control of $\mathrm{P}_{\text {lac }}$ ) resulted in a protein of approximately $42 \mathrm{kDa}$, which was smaller than the expected molecular mass of $51.8 \mathrm{kDa}$ (Fig. 4a). The reason for this is unclear. A
Table 3. Scintillation counts for the cpsE clones after $90 \%$ efficiency was reached (maximum of $10 \mathrm{~min}$ )

$c p s E(+)$ and $c p s E(-)$ indicate insert cloned in the same orientation or opposite orientation to $\mathrm{P}_{\text {lac }}$ respectively.

\begin{tabular}{|lc|}
\hline Clone & c.p.m. \\
\hline TG1/p13 cpsE (+) & 10034 \\
TG1/p13 induced cpsE (+) & 9078 \\
TG1/p34 cpsE (-) & 5663 \\
TG1/p34 induced cpsE $(-)$ & 5551 \\
TG1/pCR2.1 & 72 \\
TG1/pCR2.1 induced & $218^{*}$ \\
TG1 induced & 32 \\
TG1 ind & 37 \\
\hline
\end{tabular}

* Probably unincorporated radiolabelled glucose.

glycosyltransferase assay using membrane extracts from E. coli cells containing either p13, p34 (cpsE cloned in the opposite direction to $\mathrm{P}_{\text {lac }}$ ) or pCR2.1 (vector alone) revealed enzymic activity, detected as the incorporation of UDP- $\left[{ }^{14} \mathrm{C}\right] \mathrm{Glc}$ in extracts from TG1/p13 and TG1/p34 (Table 3). No protein band was detected in extracts from $\mathrm{p} 34$, therefore we were surprised to detect glycosyltransferase activity in these. This activity may have resulted from expression from a non-specific promoter within the vector, yielding a level of protein too low to be detected by SDS-PAGE. Use of extracts from E. coli containing the vector alone confirmed that the glycosyltransferase activity detected was genuinely due to expression of the NCFB 2393 cpsE gene. No significant difference in glucoslytransferase activity was detected between the induced and uninduced clones, suggesting that the chromosomal $\operatorname{lacl}^{\mathrm{q}}$ gene in the background E. coli TG1 is insufficient to completely repress expression from $\mathrm{P}_{\text {lac }}$ in pCR2.1. TLC analysis demonstrated that CpsE transferred only ${ }^{14} \mathrm{C}$-labelled glucose to the lipid fraction (Fig. 4b), demonstrating that the conversion of glucose to galactose by the activity of an epimerase that was reported to occur in some strains of E. coli by Kolkman et al. (1997), did not occur here. In addition, only labelled monosaccharide was detected in this study, demonstrating that CpsE transfers only a single glucose residue and is not a processive glucosyltransferase. Results from these assays combined with the data for the homology of NCFB 2393 CpsE to Xanthomonas campestris GumD (Ielpi et al., 1993), imply that NCFB 2393 CpsE transfers a glucose 1phosphate from UDP-glucose to undecaprenyl phosphate.

\section{Analysis of genes outside the cps region}

Comparison of the predicted amino acid sequences to the databases revealed that those at the $5^{\prime}$ and $3^{\prime}$ end of the region sequenced were not involved in EPS biosynthesis (Fig. 1 and Table 2). The positions of deoD 
and orf14.9 are conserved when compared to Str. thermophilus strain Sfi6 (Stingele et al., 1996); also in the CNRZ 368 strain these genes are associated with the EPS locus (Bourgoin et al., 1999).

A partial copy of the ISS1 transposase was identified next to orf14.9 in Str. thermophilus NCFB 2393. This contains only one long terminal repeat (at the $3^{\prime}$ end) identical to that found in the CNRZ 368 ISS1. The NCFB 2393 ISS1 has $64 \%$ identity (78\% similarity) to its homologue from Str. thermophilus CNRZ 368 (Bourgoin et al., 1999); $32 \%$ identity (58\% similarity) to the IS257 transposase from Sta. aureus Tn4003 (accession no. P14506) and 28\% identity (54\% similarity) to the ISS1 transposase from L. lactis IL946 (accession no. L35176). Copies of ISS1 members are widespread among industrial strains of Str. thermophilus and L. lactis, where they have been found in different positions on the chromosome including the EPS gene clusters (Bourgoin et al., 1999; Duwat et al., 1997; Mercenier \& Lemoin, 1989; Stingele et al., 1996).

A second IS element, IS1193, was also identified; this contained two $19 \mathrm{bp}$ imperfect inverted repeats and two $8 \mathrm{bp}$ perfect direct repeats, flanking a transposase gene (1246 bp). The NCFB 2393 IS1193 displayed 88\% identity (91\% similarity) at the amino acid level to IS1193 from Str. thermophilus CNRZ 368 (Bourgoin et al., 1999), $62 \%$ identity (75\% similarity) to TnpA from Str. pneumoniae WU2 (accession no. U66845), and $57 \%$ identity $(72 \%$ similarity) to IS1167 from Str. pneumoniae RX1 (accession no. M31680). A short ORF (orfM, 234 bp) has been identified within IS1193 in the opposite orientation to the transposase gene. orfM, including its putative RBS, is also present in Str. thermophilus CNRZ 368, although this was not reported by the authors. Recently, a new IS element from strain CNRZ 368, IS1194, was identified in the eps cluster (Bourgoin et al., 1998). IS1194 and other members of the IS5 subfamily all contain two ORFs, the shorter one (of unknown function) in the opposite direction to and overlapping the larger ORF which encodes the transposase gene. orf $M$ might be a remaining part of some element needed for the transposition of all IS5 members, or might be the vestige of a gene picked up during transposition between organisms.

Copies of ISS1 and IS1193 are widely present in strains of Str. thermophilus and L. lactis and it has been suggested that these could allow horizontal transfer to occur between these two organisms during co-culture in dairy manufacture (Bourgoin et al., 1996, 1999). Horizontal transfer and generation of new capsular polysaccharides or LPS as a consequence of homologous recombination between insertion elements has also been reported to occur in the CPS and LPS loci of strains of Str. pneumoniae and Sal. enterica (Morona et al., 1997; Muñoz et al., 1997; Xiang et al., 1994). The G + C content of the NCFB 2393 cps cluster is $35.6 \mathrm{~mol} \%$; this is close to the average $\mathrm{G}+\mathrm{C}$ content reported for Str. thermophilus of 37-40 mol \% (Farrow \& Collins, 1984). Interestingly, the $\mathrm{G}+\mathrm{C}$ content of four genes at the $3^{\prime}$ end of the cluster, cpsIJKL, is only of $30 \mathrm{~mol} \%$. These genes are located next to IS1193, suggesting that foreign genes could have been introduced into the NCFB 2393 cps locus by horizontal transfer. Recombination could have been facilitated by the presence of mobile elements such as IS1193 and ISS1, or by the presence of conserved genes within these clusters. Additionally, given the similarity of some of our genes to the cps genes from Str. pneumoniae, horizontal transfer between different strains of streptococci might also have occurred at some time during the evolution of these two species.

\section{ACKNOWLEDGEMENTS}

The authors would like to thank A. Jay and L. Adams for the chemical and high-performance size-exclusion chromatography analysis of the EPS; Dr A. Colhuane and Dr S. Andrews for useful advice with the computer analysis of CpsE; and Dr J. Payne for help with the sequencing of the $c p s$ operon. A.G. is supported by an EC contract no. ERB1 B104CT96739. E. A. is supported by an EC-TMR fellowship no. ERBF MBICT961816.

\section{REFERENCES}

Altshchul, S. F., Gish, W., Miller, W., Myers, E. \& Lipman, D. J. (1990). Basic local alignment search tool. J Mol Biol 215, 403-410.

Becker, A., Rüberg, S., Küster, H., Roxlau, A., Keller, M., Ivashina, T., Cheng, T., Walker, G. \& Puhler, A. (1997). The 32-kb exp gene cluster of Rhizobium meliloti directing the biosynthesis of galactoglucan. J Bacteriol 179, 1375-1384.

Bourgoin, F., Guédon, G., Pebay, M., Roussel, Y., Panis, C. \& Decaris, B. (1996). Characterization of a mosaic ISS1 element and evidence for the recent horizontal transfer of two different types of ISS1 between Streptococcus thermophilus and Lactococcus lactis. Gene 178, 15-23.

Bourgoin, F., Guédon, G., Gintz, B. \& Decaris, B. (1998). Characterization of a novel insertion sequence, IS1194, in Streptococcus thermophilus. Plasmid 40, 44-49.

Bourgoin, F., Pluvinet, A., Gintz, B., Decaris, B. \& Guédon, G. (1999). Are horizontal transfers involved in the evolution of Streptococcus thermophilus EPS synthesis loci? Gene 233, 151-161.

Bubb, W., Urashima, T., Fujiwara, R., Shinnai, T. \& Ariga, H. (1997). Structural characterization of the exocellular polysaccharide produced by Streptococcus thermophilus OR901. Carbohydr Res 301, 41-50.

Cerning, J., Bouillane, C., Desmazaud, M. J. \& Landon, M. (1988). Exocellular polysaccharide production by Streptococcus thermophilus. Biotechnol Lett 10, 255-260.

Coffey, T. J., Enright, M. C., Daniels, M., Morona, J. K., Morona, R., Hryniewicz, W., Paton, J. C. \& Spratt, B. G. (1998). Recombinational exchanges at the capsular polysaccharide biosynthetic locus lead to frequent serotype changes among natural isolates of Streptococcus pneumoniae. Mol Microbiol 27, 73-83.

Doco, T., Wieruszeski, J. \& Fournet, B. (1990). Structure of an exocellular polysaccharide produced by Streptococcus thermophilus. Carbohydr Res 198, 313-321.

Dower, W., Miller, J. \& Ragsdale, C. (1988). High efficiency transformation of $E$. coli by high voltage electroporation. Nucleic Acids Res 16, 6127-6145.

Duwat, P., Cochu, A., Ehrlich, D. \& Gruss, A. (1997). Charac- 
terization of L. lactis UV-sensitivity mutants obtained by ISS1 transposition. J Bacteriol 179, 4473-4479.

Estrem, S., Gaal, T., Ross, W. \& Gourse, R. (1998). Identification of an UP element consensus sequence for bacterial promoters. Proc Natl Acad Sci U S A 95, 9761-9766.

Farrow, J. \& Collins, M. (1984). DNA base composition, DNA-DNA homology and long chain fatty acid studies on Streptococcus thermophilus and Streptococcus salivarius. J Gen Microbiol 130, 357-362.

Fox, A., Morgan, S. \& Gilbart, J. (1989). Preparation of alditol acetates and their analysis by gas chromatography (GC) and mass spectrometry (MS). In Analysis of Carbohydrates by GLC and MS, pp. 88-115. Edited by C. Bierman \& G. McGinnis. Boca Raton, FL: CRC Press.

Gibson, T. (1984). Studies on the Epstein-Barr virus genome. $\mathrm{PhD}$ thesis. University of Cambridge.

Griffin, H., I'Anson, K. \& Gasson, M. (1993). Rapid isolation of genes from bacterial lambda libraries by direct PCR screening. FEMS Microbiol Lett 112, 49-53.

Griffin, A., Morris, V. \& Gasson, M. (1996). The $c p s A B C D E$ genes involved in polysaccharide production in Streptococcus salivarius ssp. thermophilus NCFB2393. Gene 183, 23-27.

Heinrichs, D., Yethon, J. \& Whitfield, C. (1998). Molecular basis for structural diversity in the core regions of the lipopolysaccharides of Escherichia coli and Salmonella enterica. Mol Microbiol 30, 221-232.

Higgins, D., Thompson, J. \& Gibson, T. (1994). ClustaL w: improving the sensitivity of progressive multiple sequence alignment through sequence weighting, position-specific gap penalties and weight matrix choice. Nucleic Acids Res 22, 4673-4680.

Ielpi, L., Couso, R. \& Dankert, M. (1993). Sequential assembly and polymerization of the polyprenol-linked pentasaccharide repeating unit of the xanthan polysaccharide in Xanthomonas campestris. J Bacteriol 175, 2490-2500.

Kolkman, M. A., Van der Zeijst, B. A. \& Nuijten, P. (1996). Functional analysis of glycosyl-transferases encoded by the capsular polysaccharide locus of Streptococcus pneumoniae serotype 14. J Biol Chem 272, 19502-19508.

Kolkman, M. A., Wakarchuk, W., Nuijten, P. \& Van der Zeijst, B. A. (1997). Capsular polysaccharide synthesis in Streptococcus pneumoniae serotype 14: molecular analysis of the complete $c p s$ locus and identification of genes encoding glycosyltransferases required for the biosynthesis of the tetrasaccharide subunit. Mol Microbiol 26, 197-208.

Laemmli, U. K. (1970). Cleavage of structural proteins during the assembly of the head of bacteriophage T4. Nature 277, 680-685.

Lémoine, J., Chirat, F., Wieruszeski, J. M., Strecker, G., Favre, N. \& Neeser, J. (1997). Structural characterization of the EPS produced by Streptococcus thermophilus Sfi39 and Sfi12. Appl Environ Microbiol 63, 3512-3518.

Lewington, J., Greenway, S. D. \& Spillane, B. J. (1987). Rapid small-scale preparation of bacterial genomic DNA, suitable for cloning and hybridization analysis. Lett Appl Microbiol 5, 51-53.

Low, D., Ahlgren, J., Horne, D., McMahon, D., Oberg, C. \& Broadbent, J. (1998). Role of Streptococcus thermophilus MR-1C capsular exopolysaccharide in cheese moisture retention. Appl Environ Microbiol 64, 2147-2151.

Ludowieg, J. \& Benmaman, J. (1967). Colorimetric differentiation of hexosamines. Anal Biochem 19, 80-88.

Mercenier, A. \& Lemoin, Y. (1989). Genetics of Streptococcus thermophilus: a review. J Dairy Sci 72, 3444-3454.
Morona, R., Macpherson, D., Van den Bosch, L., Carlin, N. \& Manning, P. (1995). Lipopolysaccharide with an altered O-antigen produced in E. coli K-12 harbouring mutated, cloned Shigella flexneri rfb genes. Mol Microbiol 18, 209-223.

Morona, J., Morona, R. \& Paton, J. (1997). Characterization of the locus encoding the Streptococcus pneumoniae type 19F capsular polysaccharide biosynthetic pathway. Mol Microbiol 23, 751-763.

Morona, J., Morona, R. \& Paton, J. (1999). Comparative genetics of capsular polysaccharide biosynthesis in Streptococcus pneumoniae types belonging to serogroup 19. J Bacteriol 181, 5355-5364.

Mueller, P., Keller, M., Weng, W. M., Quandt, J., Arnold, W. \& Puehler, A. (1993). Genetic analysis of the Rhizobium meliloti exoYFQ operon: ExoY is homologous to sugar transferases and ExoQ represents a transmembrane protein. Mol Plant-Microbe Interact 6, 55-65.

Muñoz, R., Mollerach, M., López, R. \& García, E. (1997). Molecular organization of the genes required for the synthesis of type 1 capsular polysaccharide of Streptococcus pneumoniae: formation of binary encapsulated pneumococci and identification of cryptic dTDP-rhamnose biosynthesis genes. Mol Microbiol 25, 79-92.

Pearson, W., Wood, T., Zhang, Z. \& Miller, W. (1997). Comparison of DNA sequences with protein sequences. Genomics 46, 24-36.

Peterson, G. (1977). A simplification of the protein assay method of Lowry et al., which is more generally applicable. Anal Biochem 83, 346-356.

Pradel, E., Parker, C. \& Schnaitman, C. (1992). Structures of the $r f a B, r f a I, r f a J$ and $r f a S$ genes of E. coli $\mathrm{K}-12$ and their roles in assembly of the lipopolysaccharide core. J Bacteriol 174, 4736-4745.

Sambrook, J., Fritsch, F. \& Maniatis, T. (1989). Molecular Cloning: a Laboratory Manual. 2nd edn. Cold Spring Harbor, NY: Cold Spring Harbor Laboratory.

Sau, S., Sun, J. \& Lee, C. (1997). Molecular characterization and transcriptional analysis of type 8 capsule genes in Staphylococcus aureus. J Bacteriol 179, 1614-1621.

Saxena, I., Brown, M., Fevre, M., Geremia, R. \& Henrissat, B. (1995). Multidomain architecture of $\beta$-glycosyl transferases: implications for mechanism of action. J Bacteriol 177, 1419-1424.

Stingele, F., Neeser, J. \& Mollet, B. (1996). Identification and characterization of the exopolysaccharide gene cluster from Streptococcus thermophilus Sfi-6. J Bacteriol 178, 1680-1690.

Stingele, F., Vincent, S., Faber, E., New ell, J., Kamerling, J. \& Neeser, J. (1999). Introduction of the exopolysaccharide gene cluster from Streptococcus thermophilus Sfi6 into Lactococcus lactis MG1363: production and characterization of an altered polysaccharide. Mol Microbiol 32, 1287-1295.

Sutherland, I. (1996). Extracellular polysaccharides. In Biotechnology, vol. 6, 2nd edn, pp. 615-652. Edited by M. Roehr, J. Rhem \& G. Reed. Weinhem: VCH.

Terzaghi, B. \& Sandine, W. (1975). Improved medium for lactic streptococci and their bacteriophages. Appl Environ Microbiol 29, 807-813.

Van Kranenburg, R., Marugg, I., Van Swam, N., Willem, N. \& De Vos, W. (1997). Molecular characterization of the plasmidencoded eps gene cluster essential for exopolysaccharide biosynthesis in Lactococcus lactis. Mol Microbiol 24, 387-397.

Van Kranenburg, R., Vos, H., Van Sw am, I., Kleerebezem, M. \& De Vos, W. (1999). Functional analysis of glycosyltransferase genes 
from L. lactis and other Gram-positive cocci : complementation, expression and diversity. J Bacteriol 181, 6347-6353.

Wang, L., Liu, D. \& Reeves, P. (1996). C-terminal half of Salmonella enterica WbaP (RfbP): is the galactosyl-1-phosphate transferase domain catalyzing the first step of the O-antigen synthesis. $J$ Bacteriol 178, 2598-2604.

Whitfield, C. (1995). Biosynthesis of lipopolysaccharide O antigens. Trends Microbiol 178, 178-185.

Wiggins, C. \& Munro, S. (1998). Activity of the yeast MNN1 $\alpha-1,3-$ mannosyltransferase requires a motif conserved in many other families of glycosyltransferases. Proc Natl Acad Sci US A 95, 7945-7950.

Xiang, S., Hobbs, M. \& Reeves, P. (1994). Molecular analysis of the $r f b$ gene cluster of a group D2 Salmonella enterica strain: evidence for its origin from an IS-mediated recombinational event between group E and D1 strains. J Bacteriol 176, 4357-4365.

Received 20 March 2000; revised 30 J une 2000; accepted 26 July 2000. 